\title{
Influencia de la impronta genómica masculina en la reproducción
}

\author{
Vasco G. C, Gil Villa AM, Piedrahita Ochoa C, Cardona Maya W, Cadavid Jaramillo A. \\ Grupo Reproducción. Sede de Investigación Universitaria (SIU). Universidad de Antioquia. Medellín, Colombia.
}

Actas Urol Esp. 2008;32(10):1004-1012

\section{RESUMEN}

INFLUENCIA DE LA IMPRONTA GENÓMICA MASCULINA EN LA REPRODUCCIÓN

Objetivo: La impronta genómica es la modificación epigenética que ocurre de manera diferencial tanto en genes específicos del oocito como del espermatozoide de acuerdo con su origen paterno o materno, permitiendo así una expresión monoalélica. En esta revisión se realiza un análisis crítico de la información relacionada con el papel que tiene la impronta masculina sobre el éxito reproductivo.

Metodología: Se hizo una búsqueda bibliográfica sobre algunos de los componentes que regulan la impronta geonómica masculina y el posible papel sobre los eventos reproductivos como la espermatogénesis y el desarrollo placentario y embrionario.

Resultados: Este análisis de la literatura permitió valorar que los cambios estructurales, genéticos y epigenéticos que ocurren durante la formación del gameto masculino, pueden tener repercusiones en el desarrollo embrionario, principalmente en la formación de tejidos extraembrionarios como la placenta.

Conclusión: Las alteraciones en los mecanismos moleculares implicados en el proceso de metilación del ADN durante la espermatogénesis, pueden generar errores en el patrón normal de expresión requerido para el adecuado desarrollo de los componentes feto-placentarios.

Palabras clave: Espermatozoide. Impronta. Fertilidad. Desarrollo embrionario. Placenta.

\section{ABSTRACT}

INFLUENCE OF THE MALE GENOMIC IMPRINTING ON THE REPRODUCTION

Objective: Genomic imprinting is the epigenetic change that occurred differentially in the specific genes in spermatozoa and oocyte according to their paternal or maternal origin, thus allowing a monoallelic expression. This review is a critical analysis of the published information relating to the role of the male imprinting on the successful reproduction.

Methods: We performed a literature search on some of the components that regulate the male genomic imprinting and the possible role on reproductive events such as spermatogenesis, and placental and embryo development.

Results: The literature analysis allowed us to appreciate structural, genetic and epigenetic changes occurring during the formation of the male gamete that could have an impact on embryo development, mainly in the formation of extraembryonic tissues as the placenta.

Conclusion: Alterations in the molecular mechanisms involved in the sperm DNA methylation during the spermatogenesis, could induce alterations in the normal pattern of expression required in the fetal-placental components development.

Keywords: Spermatozoa. Genomic imprinting. Fertility. Embryo development. Placenta.

$\mathrm{L}$ a información epigenética se relaciona con modificaciones funcionales en los genes que se heredan a la progenie, sin involucrar cambios en la secuencia del $\mathrm{ADN}^{1,2}$. En las células eucariotas existe una marca genética conocida como impronta genómica, que actúa como la modificación epigenética diferencial de las secuencias encargadas de regular la expresión de genes específicos en el oocito y en el espermatozoide, dando origen a una sola copia del gen de acuerdo a su origen parental, el cual después de la fecundación, se expresará en el embrión ${ }^{3,4}$. Es importante resaltar que no todo el genoma funciona bajo la influencia de la impronta, debido a que luego de la fecundación, el nuevo 
genoma sufre una reprogramación post-cigótica que ocurre antes de la expresión de genes específicos durante el desarrollo embrionario, permitiendo que la regulación propia de la impronta ocurra desde la etapa de célula germinal hasta la embriogénesis de la descendencia $^{5}$. En los genes que experimentan impronta paterna, el alelo que proviene del padre es epigenéticamente modificado con el fin de reprimir su transcripción, asegurando que el embrión exprese el alelo de un solo progenitor, en este caso el de la madre; lo inverso ocurre en los genes maternos improntados. Todo ésto pone de manifiesto que las contribuciones genéticas materna y paterna son funcionalmente diferentes, al menos para varias regiones genómicas y que este evento es crucial en el desarrollo de los tejidos embrionarios y extra-embrionarios ${ }^{6-8}$.

La regulación epigenética de la transcripción que ocurre en la impronta genómica, involucra un complejo reordenamiento en la estructura de la cromatina, debido principalmente a la metilación del $\mathrm{ADN}$, lo cual es importante tanto en la regulación y el control de la replicación como en la expresión génica de las células eucarióticas $^{9,10}$. En los gametos masculino y femenino, la metilación del $\mathrm{ADN}$ desaparece en las células germinales primordiales después de la fecundación y durante el desarrollo embrionario, para restablecerse nuevamente durante la gametogénesis ${ }^{4,11}$ (Fig. 1).

La metilación del ADN en los mamíferos, ocurre sobre los residuos de citosina que están presentes en los motivos de dinucleótidos formados por la 5 citosina y la guanosina, conocidos como islas $\mathrm{CpG}$, donde el grupo metilo $\left(\mathrm{CH}_{3}\right)$ se une al carbono 5 de la citosina formando la metilcitosina-5 en las Regiones Diferencialmente Metiladas (DMR) y en las Regiones de Control de la Impronta (ICR) ${ }^{4,12}$. Las DMR pueden tener diversas propiedades, algunas son metiladas en el alelo silenciado mientras otras son metiladas en la copia activa $^{11}$. Una de las DMR mejor caracterizada en el modelo murino, está localizada en el segmento 15 del brazo corto del cromosoma 11 (11p15) e incluye genes de expresión monoalélica que se encuentran muy cerca en el cromosoma como Igf2 y H19, los cuales se transcriben exclusivamente del alelo no metilado de origen paterno y materno, respectivamente. La expresión recíproca de estos dos genes, identificados en murinos pero también observados en humanos, refleja una interacción que involucra secuencias reguladoras compartidas, localizadas corriente arriba del gen $H 19^{13,14}$.

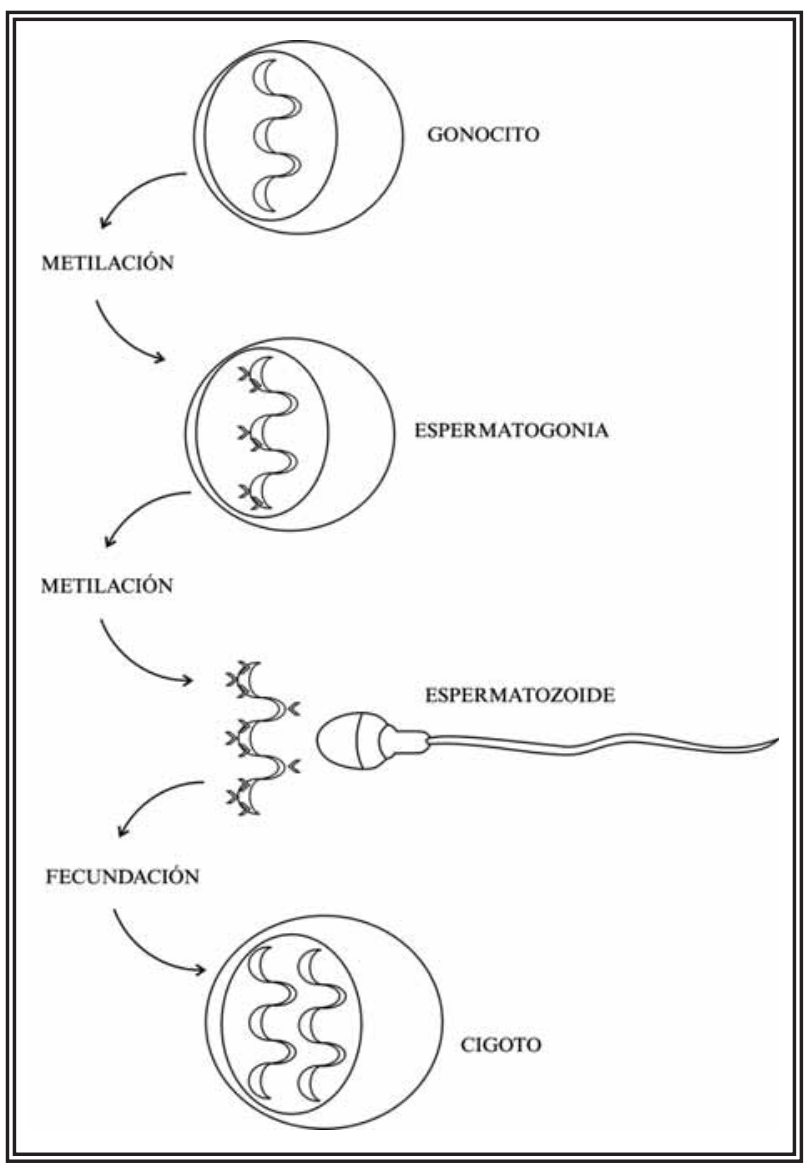

FIGURA 1. Las improntas paternas desaparecen durante el desarrollo de la célula germinal. Cuando el espermatozoide está maduro adquiere un patrón de metilación correcto sobre el genoma. Después de la fecundación, el genoma paterno experimenta una desmetilación global de secuencias no improntadas y los genes improntados estarán protegidos de este proceso hasta el subsiguiente desarrollo embrionario, en donde las células germinales primordiales del embrión experimentarán desmetilación para borrar las improntas heredadas.

El CTCF es una proteína con once dominios dedos de zinc que reconoce la secuencia CCCTC y es un regulador somático de la expresión de genes improntados, los cuales se unen a secuencias blanco específicas del ADN y tienen un papel general en el mantenimiento de patrones de metilación diferenciales en las células somáticas ${ }^{15}$. Para el caso de la ICR de Igf2/H19, encargada de la regulación coordinada de estos genes, el sitio de unión a CTCF, está sin metilar en el cromosoma materno y la unión de CTCF a este sitio promueve la activación del gen H19 y el silenciamiento del gen Igf2, debido a que la interacción entre la proteína CTCF y la ICR materna sin metilar inhibe la interacción entre los promotores del 
gen Igf2 y el potenciador corriente abajo del gen. En contraste, en el cromosoma paterno, el sitio de unión a CTCF está metilado y es incapaz de unirse con éste, activando el Igf2 y silenciando el H1916-18.

El ADN metilado de origen parental en el embrión se localiza mayormente en genes improntados de novo; sin embargo, en etapas tempranas de su desarrollo pierde su metilación en las secuencias improntadas, lo cual parece suceder en un orden específico de acuerdo con su origen paterno o materno ${ }^{19}$. En los murinos, el genoma paterno es significativa y activamente demetilado entre 6-8 horas después de la fecundación, antes de comenzar la replicación del $\mathrm{ADN}$, mientras que el genoma materno es demetilado después de varias divisiones celulares. Esta desmetilación activa del genoma paterno puede estar asociada con el remodelamiento epigenético de la cromatina espermática para establecer programas de desarrollo específicos durante la embriogénesis temprana ${ }^{20}$.

La metilación del ADN en las ICR o en las DMR requiere de una enzima perteneciente a la familia de las ADN citosina metiltransferasas (Dnmt) que tiene tres isoformas: Dnmt1 y Dnmt3 con funciones esenciales para la viabilidad embrionaria, y la isoforma Dnmt2 que aún no tiene bien identificada su acción transmetilasa ${ }^{8,12,21,22}$. Específicamente, en el modelo murino la isoforma Dnmt1 es responsable de mantener la metilación del ADN en las células somáticas ${ }^{23}$ y la Dnmt3, con sus dos tipos Dnmt3a y Dnmt3b, es importante para la metilación de novo en células madre embrionarias y en el embrión postimplantado ${ }^{21}$. Además se ha encontrado una isoforma llamada Dnmt3L que carece de actividad enzimática e interactúa con Dnmt3a y Dnmt3b modulando la metilación de novo de genes improntados en el gameto femenino; recientemente se describió el homólogo humano DNMT3L con una actividad similar ${ }^{24-26}$. Así las enzimas Dnmt1 y Dnmt3 se asocian a los genes improntados eliminando la metilación y restableciéndola nuevamente durante la gametogénesis, y por tal motivo los patrones de metilación maternos y paternos heredados por un descendiente varón, se borran en la línea germinal masculina y se sustituyen por el patrón paterno que será llevado por cada espermatozoide; de la misma manera, cada oocito producido por una hembra llevará el patrón materno de metilación ${ }^{4,27}$.

\section{IMPRONTA GENÓMICA EN LA ESPERMATOGÉNESIS}

La espermatogénesis es la diferenciación de las células germinales masculinas desde espermatogonias a espermatozoides maduros; es un proceso continuo que se inicia durante la pubertad y está caracterizado por un estadío premeiótico llamado espermatogoniogénesis, un estadío meiótico y otro postmeiótico o espermiogénesis ${ }^{4,28}$. El empaquetamiento del $\mathrm{ADN}$ en el núcleo espermático ocurre durante la espermiogénesis y es diferente al que se da lugar en las células somáticas debido a que la mayoría de las histonas, proteínas encargadas del empaquetamiento del $\mathrm{ADN}$ en las células somáticas, son removidas y sustituidas por proteínas de transición (TP1 y TP2), las cuales son reemplazadas posteriormente por proteínas nucleares denominadas protaminas (PRM1 y PRM2) ${ }^{29,30}$. Se ha observado que la estructura del núcleo espermático puede ser un punto crítico para el establecimiento de los patrones epigenéticos paternos durante la gametogénesis y, además, provee un ambiente protector de la información epigenética paterna, la cual es de gran importancia para el desarrollo pre y postnatal ${ }^{31,32}$.

En las células germinales primordiales, los genes heredados improntados borran sus marcas de metilación y luego, durante la espermatogénesis, se lleva a cabo la metilación monoalélica de novo, específica de origen paterno ${ }^{33}$. Este proceso difiere entre los gametos masculino y femenino, ya que mientras la metilación materna se establece durante el crecimiento del oocito en ausencia de la replicación del ADN, el establecimiento de la metilación paterna, es un proceso continuo que ocurre en las células madre espermatogónicas en división mitótica como también en los espermatocitos derivados de estas divisiones ${ }^{34,35}$. Esta cronología de imposición de las improntas de metilación se correlaciona con el potencial que tiene el núcleo del espermatocito primario para generar descendencia cuando son microinyectados en oocitos maduros al usar técnicas de reproducción asistida como inyección intracitoplasmática de espermatozoidesantes (ICSI) ${ }^{36,37}$.

\section{Regulación de la impronta espermática}

En teoría existen dos tipos de factores que podrían estar involucrados en el direccionamiento de la metilación del ADN paterno en las ICR en una etapa determinada de la línea germinal, aquellos que pro- 
tegen de la metilación a estas regiones y los que la inducen. En la ICR H19/Igf2 se identificó una actividad específica de unión al ADN que fue restringida a la línea germinal masculina y estaba incrementada en el testículo de los neonatos ${ }^{38}$. Un factor denominado BORIS (del ingles, Brother of the Regulador of Imprinted Sites), el cual se expresa en el testículo, podría estar directamente involucrado en el establecimiento de las marcas de metilación durante la diferenciación de la célula germinal masculina $^{39,40}$. BORIS posee los mismos 11 dominios dedo de zinc, pero protege diferentes aminoácidos y carboxilos terminales de CTCF. Los datos funcionales sugieren que, durante la espermatogénesis, la metilación de novo del $\mathrm{ADN}$ paterno podría estar asociada con el silenciamiento de CTCF y la activación de BORIS. Adicionalmente, se ha observado una alta regulación secuencial de BORIS en las células CTCF negativas y, de CTCF en las células BORIS negativas, en asociación con la eliminación y restablecimiento de las marcas de metilación, respectivamente $^{39}$. De acuerdo a estos datos, BORIS podría estar participando en la eliminación temprana de las marcas de metilación y podría estar asociado con las aún poco estudiadas ADN desmetilasas, como también en la ocupación selectiva de secuencias CTCF blanco en las ICR maternamente metiladas, protegiendo las CTCF de la metilación ${ }^{40}$. En general, el establecimiento de la impronta genómica paterna durante la espermatogénesis, ha sido ligado a la creación de un patrón de metilación de novo paterno en las ICR, lo cual ocurre en las células premeióticas y en los espermatocitos tempranos e involucra a la ADN metiltransferasa Dnmt3a ayudada por su cofactor Dnmt3L.

\section{Modificaciones de la cromatina espermática}

Los genes improntados se expresan bialélicamente como si estas modificaciones epigenéticas no estuvieran presentes, debido a que estas últimas no tienen influencia sobre la maquinaria transcripcional del gameto ${ }^{33,41}$. Aunque la metilación del ADN podría aparecer como el candidato más probable para transmitir las improntas parentales al futuro embrión, la información en células somáticas provee evidencia que permite pensar que la impronta es una entidad dinámica que involucra otras modificaciones epigenéticas ${ }^{6}$. Adicionalmente, se conoce que existe una desmetilación activa del genoma paterno justo después de la fecundación, lo cual sugiere que una marca ADN-metilo adquirida durante la espermatogénesis podría llevar consigo una modificación específica de histona, que a su vez puede proteger esta marca metilo particular de la desmetilación global, por medio del reclutamiento de un factor "protector", o llevando la información de la impronta para que durante el desarrollo embrionario, sea convertida en una marca metilo ${ }^{4,20}$.

Las ADN citosina metiltransferasas Dnmt3a y su homóloga Dnmt3L, actúan sobre la cromatina espermática como co-represoras, llevando consigo las enzimas histona deacetilasas (HDAC), cuya actividad podría ser importante en un sistema transcripcionalmente reprimido para que se constituyan improntas genómicas específicas del sexo ${ }^{42-44}$. Adicionalmente, se ha observado que una modificación postraduccional de la Dnmt3a por sumoilación (unión covalente a determinadas proteínas de un péptido similar a la ubiquitina denominado SUMO) ocasiona una alteración en su habilidad para interactuar con las HDAC 1 y 2, suprimiendo así su capacidad de reprimir la transcripción ${ }^{45}$.

\section{Alteraciones en la espermatogénesis relacionadas con la impronta}

Con el fin de determinar si la incorrecta impronta genómica paterna podría asociarse con la alteración de la espermatogénesis, Marques y cols., extrajeron ADN espermático de 123 muestras de semen de individuos normozoospérmicos y oligozoospérmicos, y encontraron que algunos hombres oligozoospérmicos presentaban espermatozoides con metilación defectuosa del sitio de unión a CTCF entre los genes IGF2 y H19. Adicionalmente, hallaron que aunque las improntas maternas han sido borradas de todos los espermatozoides, el gen H19 improntado paternamente está hipometilado en algunos espermatozoides de los individuos oligozoospérmi$\cos \mathrm{y}$, por consiguiente, cualquier embrión derivado de uno de estos espermatozoides hipometilados podría tener una expresión alterada de los genes improntados H19 e IGF2, cuyo efecto aún no se conoce con suficiente claridad en humanos ${ }^{17}$. Por su parte, Kobayashi y cols., evidenciaron que en el eyaculado de pacientes oligozoospérmicos, el estado de metilación de las DMR de al menos siete locus evaluados, está alterado en la mayoría de los individuos, sugiriendo que los espermatozoides que se 
emplean para ICSI, a los cuales no se les hace una evaluación previa que determine el estado de metilación de las DMR, se aumenta el riesgo que un patrón alterado sea heredado por la descendencia ${ }^{46}$.

\section{IMPRONTA, DESARROLLO PLACENTARIO Y EMBRIONARIO}

El primer acontecimiento que sucede al momento de la diferenciación embrionaria, ocurre en el estadío de mórula, donde la masa celular interna se separa de la capa celular externa o trofoectodermo, que dará origen al tejido placentario. Durante la diferenciación celular de las blastómeras influyen factores genéticos que promueven el establecimiento del linaje trofoblástico y se ha demostrado el requerimiento de la impronta genómica parental para su diferenciación y mantenimiento ${ }^{47}$. Se han propuesto diferentes teorías para explicar el significado del etiquetamiento genómico en los mamíferos, una de ellas es la "hipótesis del conflicto genético" propuesta por Moore y Haig en 1991, la cual sugiere que por medio de la impronta, el macho y la hembra logran que sus descendientes usen las fuentes maternas como resultado de dos estrategias diferentes, el padre tiende a favorecer la talla de la descendencia sin considerar las fuentes maternas y la madre responde igualmente a la demanda fetal de nutrientes sin comprometer embarazos futuros ${ }^{48}$. De este modo, el crecimiento normal del feto es el resultado del balance de estas estrategias opuestas basadas en la expresión monoalélica en la placenta debido a que la mayoría de los genes maternos expresados actúan como supresores del crecimiento, mientras los expresados paternamente lo promueven ${ }^{11,47,49}$.

Cerca de 100 genes de los gametos masculino y femenino en los mamíferos, podrían estar improntados apropiadamente de manera parental-específica para permitir un desarrollo placentario y embrionario normal. Así, los genes expresados del padre como Plag1 (gen adenoma pleomórfico tipo 1), Peg1/Mest (gen 1 expresado paternamente/ transcrito específico de mesodermo), Igf2 (factor insulinoide de crecimiento tipo II) y Peg3 (gen 3 expresado paternamente), mejoran el crecimiento fetal y placentario, mientras que los genes expresados de la madre como $\operatorname{Ig} f 2 r$ (receptor del factor insulinoide de crecimiento tipo II), Grab10 (proteína de unión a la microglobulina alfa 2 relacionada con proteína G),
H19 (gen H19), Cdkn1c (inhibidor de kinasa dependiente de ciclina 1C), Tssc3 (candidato del fragmento génico 4 transferible subcromosómico de supresión de tumor), Mash2 (factor de trascripción básica hélice-asa-hélice) y Meg3 (gen 3 expresado maternamente), lo restringen ${ }^{11,50}$. De esta forma por ejemplo, el bajo peso fetal podría ser causado por la disminución en la expresión paterna de un gen promotor del crecimiento o por la activación alterada del alelo paterno de un gen que restringe el crecimiento y que está normalmente silenciado ${ }^{11,50}$.

La impronta genómica influye sobre la expresión de Igf-2, gen que se transcribe del alelo paterno y en esta vía muchos estudios han apuntado a reconocer el papel de este factor de crecimiento sobre la diferenciación trofoblástica y el proceso invasivo. En estudios con cobayos se encontraron diferencias en el tamaño de las placentas y la invasión trofoblástica en hembras grávidas a las que se les inyectó vía intravenosa la proteína IGF2 con respecto a las hembras control; los hallazgos se correlacionaron con el tratamiento, debido a que se mejoró el tamaño de la camada, el peso promedio al nacer y disminuyó el número de reabsorciones embrionarias ${ }^{51}$. Posteriormente en ratones se demostró que IGF2 promueve la diferenciación in vitro de células trofoblásticas aisladas del cono ectoplacentario en células trofoblásticas gigantes, población celular que en murinos invade la decidua y las arterias uterinas maternas $^{52}$. En humanos se ha encontrado que la población trofoblástica que posee más cantidad de mRNA de IGF2 es el citotrofoblasto extravelloso (evCTB) el cual invade el lecho materno; McKinnon $\mathrm{T}$ y cols. en 2001, empleando evCTB y una línea celular derivada de esta población trofoblástica, observaron que el IGF2 promueve la invasión y además demostraron que este factor de crecimiento actúa a través del receptor del factor de crecimiento insulinoide tipo 2 (IGFR-2), receptor tirosina kinasa, activando la vía de las protein-kinasas asociadas a mitógenos (MAPKs), ERK-1 y ERK-253.

En algunos mamíferos como primates, roedores y rumiantes, la impronta genómica está conservada en la estructura placentaria facilitando varios tipos de asociaciones anatómicas por las interacciones entre las células que se encuentran en este linaje celular y que son indispensables para el desarrollo del embrión ${ }^{6,7}$. La comprensión de esta interacción puede ser clínicamente relevante debido a que las 
alteraciones en los eventos epigenéticos tempranos ocurridos durante la espermatogénesis podrían presentarse acompañadas de algunas morbilidades gestacionales como restricción del crecimiento intrauterino y preeclampsia, que en su etiología se caracterizan por asociarse a una menor invasión trofoblástica, una marcada disminución en la transformación de las arterias espirales uterinas y placentas más pequeñas ${ }^{54}$.

\section{Papel de la impronta genómica en el desarrollo embrionario}

Uno de los más interesantes ejemplos del papel de la impronta sobre el desarrollo embrionario es el caso del embarazo molar, debido a que éste evidencia que tanto los genes de origen materno como paterno son esenciales para el desarrollo embrionario normal. La mola es el resultado de una sobreproducción de tejido extraembrionario acompañada con una reducción significativa de los componentes que forman el embrión. Usando el modelo murino, varios investigadores lograron cambiar el pronúcleo masculino en oocitos, después de ser fecundados, por un pronúcleo de origen femenino generando un embrión en el cual todos los cromosomas son de origen femenino ${ }^{55}$; estos embriones son denominados ginogenéticos y se ha observado que presentan alteraciones en el desarrollo embrionario. Básicamente, no se han encontrado componentes extraembrionarios aunque se observa un exagerado desarrollo embrioblástico ${ }^{56}$. En contraste a lo anterior, en un embrión androgenético, que contiene todos sus cromosomas de origen paterno, se observan fallas en el desarrollo del embrioblasto mientras que el trofoblasto prolifera excesivamente dando como resultado una mola hidatidiforme ${ }^{57}$. Esta evidencia permitió elucidar que algunos genes de origen materno son necesarios para el buen desarrollo de un embrión, mientras que los componentes extraembrionarios dependen de la presencia de genes paternos activos, lo cual sugiere que el desarrollo embrionario está regulado por el proceso de la impronta genómica.

\section{Errores en la impronta y sus implicaciones en la muerte embrionaria}

Una posible causa de muerte embrionaria temprana es la disomía uniparental (DUP) ${ }^{34}$, la cual es definida como la presencia de un par de cromoso- mas completo o una región cromosómica, heredada de uno de los padres y ninguna del otro. Se ha demostrado que la fecundación uniparental altera el desarrollo normal ya que un subconjunto de genes funciona de manera diferente, dependiendo de si la transmisión es paterna o materna. La mayoría de los casos de DUP se originan después de un evento mitótico de salvamento seguido de la formación de un cigoto trisómico debido a un error de no disyunción durante la meiosis I o la meiosis II. Dichos errores ocurren prevalentemente en la meiosis femenina y los eventos de no disyunción son más comunes durante la meiosis I que durante la meiosis II. La impronta puede estar involucrada en el resultado del embarazo incluso en presencia de un mosaicismo trisómico y cuando el cromosoma involucrado en la aneuploidía es biparental; así, en el caso de dos copias de un gen improntado o genes expresados por el cromosoma parental, se espera que la expresión sea doble y esto podría afectar negativamente el desarrollo de la unidad feto-placentaria $^{11,49}$. Los efectos de la DUP en los murinos van desde muerte embrionaria temprana a gestaciones a término con fenotipos normales. Los reportes sobre DUP en humanos han hecho posible identificar las regiones cromosómicas asociadas, con consecuencias fenotípicas en el feto o en el neonato, pero se conoce poco de la relación entre la DUP y los abortos de primer trimestre. Algunas regiones cromosómicas de DUP murinas (y humanas) que están asociadas con la muerte embrionaria temprana y neonatal son: el cromosoma 20 materno y paterno distal (20q), el cromosoma 6 materno proximal (7q), el cromosoma 7 materno proximal (19p y q), el cromosoma 7 materno y paterno distal (11p), el cromosoma 12 materno y paterno distal (14q) y el cromosoma 17 paterno proximal $(6 q)^{11}$.

\section{Potenciales riesgos epigenéticos de las Técnicas de Reproducción Asistida (ART)}

En los últimos 25 años, ha incrementado rápidamente la frecuencia de los nacimientos en donde han intervenido las ART. Estos procedimientos como la fertilización in vitro y el ICSI se han considerado seguros, pero a su vez se ha sugerido que pueden producir bajo peso fetal y mayor riesgo que el neonato contenga alteraciones en la impronta genómica que conducen a la presentación de diferentes sindromes como el Beckwith-Wiedemann y el 
Angelman 58,59. Adicionalmente, el retinoblastoma y algunos defectos en el desarrollo neuronal, han sido sólo tentativamente ligados a las ART, sin embargo es conveniente destacar que los procesos epigenéticos tienen un papel importante en la regulación de la expresión génica en el desarrollo y en el cáncer; por este motivo, se requieren futuras investigaciones a largo plazo enfocadas en la salud de las cohortes de niños concebidos mediante ART y en las consecuencias epigenéticas de los protocolos empleados en estas tecnologías. De otro lado, a pesar que se ha mostrado que las alteraciones de la impronta son complicaciones raras de estas tecnologías, los errores epigenéticos podrían explicar un espectro mucho más amplio de las complicaciones relacionadas a la reproducción asistida que las reconocidas actualmente ${ }^{59}$.

\section{CONCLUSIÓN}

En esta revisión se hace énfasis en las importantes implicaciones que tiene la impronta genómica masculina para la comprensión de la regulación epigenética del desarrollo embrionario y se ponen en evidencia los fenómenos genéticos y epigenéticos que influyen en el crecimiento y desarrollo de los tejidos embrionarios y extraembrionarios.

Es necesario resaltar la importancia de la metilación, como mecanismo general de la impronta, ya que debe mantenerse para proteger de la desmetilación que le ocurre al ADN durante el período de preimplantación embrionaria. El conocimiento de los acontecimientos y mecanismos moleculares implicados en el proceso de metilación del ADN espermático proporciona fundamentos para una mejor comprensión de los eventos epigenéticos que influyen sobre el espermatozoide maduro, ya que éste puede verse afectado en las diferentes fases de la espermatogénesis posibilitando errores en la información epigenética albergada en el núcleo y generando alteraciones en el patrón normal de expresión, que es requerido para el desarrollo de los componentes feto-placentarios. Un ejemplo es el IGF2 y su influencia sobre el desarrollo de la placenta, ya que la actividad transcripcional de dicho factor desempeña un papel importante para la placentación y revela el aporte de la epigénesis, puntualmente la impronta de origen paterno.

Durante el fenómeno de invasión trofoblástica se han identificado muchos factores fisiológicos e histológicos que ejercen efectos en el microambiente sobre las células trofoblásticas, entre los cuales se destacan moléculas de adhesión celular, proteínas de matriz extracelular y factores de crecimiento y, es la red de interacciones establecida por todos estos elementos, aunados al control transcripcional dependiente de la impronta parental, lo que define la invasión como un fenómeno indispensable para la placentación.

Para mejorar el entendimiento de la relevancia que tienen la expresión defectuosa de los genes improntados en el crecimiento de la placenta y del feto, sería importante estudiar los casos con alteraciones en el crecimiento fetal, usando una combinación de herramientas citogenéticas y moleculares, verificando el estado biparental del cariotipo del feto y de la placenta, usando métodos altamente sensibles como la electroforesis capilar para analizar los paneles informativos de los polimorfismos del ADN localizados en las regiones cromosómicas, en las cuales se conoce o se sospecha la existencia de los genes improntados. Por otra parte la evaluación del nivel de expresión de los genes improntados en la placenta de los embarazos que muestren una tasa anormal de crecimiento son importantes para tratar de asociar los resultados con la morfología del tejido extraembrionario y así encontrar el efecto de las alteraciones de los genes improntados sobre la placenta de los fetos que crecen anormalmente.

\section{Agradecimientos}

Este trabajo fue financiado por la Universidad de Antioquia (CODI). AM G-V y WC-M son becarios de COLCIENCIAS.

\section{REFERENCIAS}

1. Feil R, Kelsey G. Genomic imprinting: a chromatin connection. Am J Hum Genet. 1997;61(6):1213-1219.

2. Lorincz MC, Schubeler D, Hutchinson SR, Dickerson DR, Groudine M. DNA methylation density influences the stability of an epigenetic imprint and Dnmt3a/b-independent de novo methylation. Mol Cell Biol. 2002;22(21):7572-7580.

3. Bender J. Chromatin-based silencing mechanisms. Curr Opin Plant Biol. 2004;7(5):521-526.

4. Rousseaux S, Caron C, Govin J, Lestrat C, Faure AK, Khochbin S. Establishment of male-specific epigenetic information. Gene. 2005;345(2):139-153.

5. García R. Epigenética: una explicación de las enfermedades hereditarias. Perinatol Reprod Hum. 2003;17:57-60.

6. Swales AK. Genomic imprinting and reproduction. Reproduction. 2005; 130(4):389-399.

7. Wagschal A. Genomic imprinting in the placenta. Cytogenet Genome Res. 2006;113(1-4):90-89.

8. Cirio MC, Ratnam S, Ding F, Reinhart B, Navara C, Chaillet JR. Preimplantation expression of the somatic form of Dnmt1 suggests a role in the inheritance of genomic imprints. BMC Dev Biol. 2008;8:9. 
9. Rice MR, Blumenthal RM. Recognition of native DNA methylation by the PvuII restriction endonuclease. Nucleic Acids Res. 2000;28(16):3143-50.

10. Baroux C, Pien S, Grossniklaus U. Chromatin modification and remodeling during early seed development. Curr Opin Genet Dev. 2007;17(6):473-479.

11. Miozzo M, Simoni G. The role of imprinted genes in fetal growth. Biol Neonate. 2002;81(4):217-228.

12. Liu K, Wang YF, Cantemir C, Muller MT. Endogenous assays of DNA methyltransferases: Evidence for differential activities of DNMT1, DNMT2, and DNMT3 in mammalian cells in vivo. Mol Cell Biol. 2003;23(8):2709-2719.

13. Thorvaldsen JL. Developmental profile of H19 differentially methylated domain (DMD) deletion alleles reveals multiple roles of the DMD in regulating allelic expression and DNA methylation at the imprinted H19/Igf2 locus. Mol Cell Biol. 2006;26(4): 1245-1258.

14. Hartmann S, Bergmann M, Bohle RM, Weidner W, Steger K. Genetic imprinting during impaired spermatogenesis. Mol Hum Reprod. 2006;12(6):407-411.

15. Rand E, Ben-Porath I, Keshet I, Cedar H. CTCF elements direct allele-specific undermethylation at the imprinted H19 locus. Curr Biol. 2004;14(11):1007-1012.

16. Pfeifer K. Mechanisms of genomic imprinting. Am J Hum Genet. 2000;67(4):777-787

17. Marques CJ, Carvalho F, Sousa M, Barros A. Genomic imprinting in disruptive spermatogenesis. Lancet. 2004;363(9422): 1700-1702.

18. Sasaki H, Matsui Y. Epigenetic events in mammalian germ-cell development: reprogramming and beyond. Nat Rev Genet. 2008;9(2):129-140.

19. McLaren RJ, Montgomery GW. Genomic imprinting of the insulin-like growth factor 2 gene in sheep. Mamm Genome. 1999;10 (6):588-591.

20. Mayer W, Niveleau A, Walter J, Fundele R, Haaf T. Demethylation of the zygotic paternal genome. Nature. 2000;403(6769):501502 .

21. Okano M, Bell DW, Haber DA, Li E. DNA methyltransferases Dnmt3a and Dnmt3b are essential for de novo methylation and mammalian development. Cell. 1999;99(3):247-257.

22. Yang L, Andrade MF, Labialle S, Moussette S, Geneau G, Sinnett D, et al. Parental effect of DNA (Cytosine-5) methyltransferase 1 on grandparental-origin-dependent transmission ratio distortion in mouse crosses and human families. Genetics. 2008;178(1):35-45.

23. Jaenisch R, Bird A. Epigenetic regulation of gene expression: how the genome integrates intrinsic and environmental signals. Nat Genet. 2003;33 Suppl:245-254

24. Hata K, Okano M, Lei H, Li E. Dnmt3L cooperates with the Dnmt3 family of de novo DNA methyltransferases to establish maternal imprints in mice. Development. 2002;129(8):19831993.

25. Margot JB, Ehrenhofer-Murray AE, Leonhardt H. Interactions within the mammalian DNA methyltransferase family. BMC Molecular Biology. 2003;4(1):7.

26. Suetake I, Shinozaki F, Miyagawa J, Takeshima H, Tajima S. DNMT3L stimulates the DNA methylation activity of Dnmt3a and Dnmt3b through a direct interaction. J Biol Chem. 2004;279(26):27816-27823

27. Turek-Plewa J, Jagodzinski PP. The role of mammalian DNA methyltransferases in the regulation of gene expression. Cell Mol Biol Lett. 2005;10(4):631-647.

28. Yanagimachi R. "Fertilization in Mammalian". Knobil E NJ. ed. New York; 1994
29. Agarwal A, Said TM. Role of sperm chromatin abnormalities and DNA damage in male infertility. Hum Reprod Update. 2003;9(4):331-345

30. Martins RP, Krawetz SA. Nuclear organization of the protamine locus Soc Reprod Fertil Suppl. 2007;64:1-12.

31. Barone JG, De Lara J, Cummings KB, Ward WS. DNA organization in human spermatozoa. J Androl. 1994;15(2):139-144.

32. Erenpreiss J, Spano M, Erenpreisa J, Bungum M, Giwercman A. Sperm chromatin structure and male fertility: biological and clinical aspects. Asian J Androl. 2006;8(1):11-29.

33. Mann JR. Imprinting in the germ line. Stem Cells. 2001;19(4): 287-294.

34. Kerjean A, Dupont JM, Vasseur C, Le Tessier D, Cuisset L, Paldi A, et al. Establishment of the paternal methylation imprint of the human H19 and MEST/PEG1 genes during spermatogenesis. Hum Mol Genet. 2000;9(14):2183-2187.

35. Lucifero D, Mann MR, Bartolomei MS, Trasler JM. Gene-specific timing and epigenetic memory in oocyte imprinting. Hum Mol Genet. 2004;13(8):839-849.

36. Kimura Y, Tateno H, Handel MA, Yanagimachi R. Factors affecting meiotic and developmental competence of primary spermatocyte nuclei injected into mouse oocytes. Biol Reprod. 1998;59(4):871-877.

37. Georgiou I, Syrrou M, Pardalidis N, Karakitsios K, Mantzavinos T, Giotitsas N, et al. Genetic and epigenetic risks of intracytoplasmic sperm injection method. Asian J Androl. 2006;8(6): 643-673.

38. Bowman AB, Levorse JM, Ingram RS, Tilghman SM. Functional characterization of a testis-specific DNA binding activity at the H19/Igf2 imprinting control region. Mol Cell Biol. 2003;23(22): 8345-8351.

39. Klenova EM, Morse HC, 3rd, Ohlsson R, Lobanenkov VV. The novel BORIS + CTCF gene family is uniquely involved in the epigenetics of normal biology and cancer. Semin Cancer Biol. 2002;12(5):399-414.

40. Loukinov DI, Pugacheva E, Vatolin S, Pack SD, Moon H, Chernukhin I, et al. BORIS, a novel male germ-line-specific protein associated with epigenetic reprogramming events, shares the same 11-zinc-finger domain with $\mathrm{CTCF}$, the insulator protein involved in reading imprinting marks in the soma. Proc Natl Acad Sci U S A. 2002;99(10):6806-6811.

41. Villar AJ, Eddy EM, Pedersen RA. Developmental regulation of genomic imprinting during gametogenesis. Dev Biol. 1995; 172 (1):264-271.

42. Fuks F, Burgers WA, Godin N, Kasai M, Kouzarides T. Dnmt3a binds deacetylases and is recruited by a sequence-specific repressor to silence transcription. Embo J. 2001;20(10):25362544

43. Deplus R, Brenner C, Burgers WA, Putmans P, Kouzarides T, de Launoit Y, et al. Dnmt3L is a transcriptional repressor that recruits histone deacetylase. Nucleic Acids Res. 2002;30(17): 3831-3838

44. Aapola U LI, Peterson P. Imprinting regulator DNMT3L is a transcriptional repressor associated with histone deacetylase activity. Nucleic Acids Res. 2002;30(16):3602-3608.

45. Ling Y, Sankpal UT, Robertson AK, McNally JG, Karpova T, Robertson KD. Modification of de novo DNA methyltransferase 3a (Dnmt3a) by SUMO-1 modulates its interaction with histone deacetylases (HDACs) and its capacity to repress transcription. Nucleic Acids Res. 2004;32(2):598-610.

46. Kobayashi H, Sato A, Otsu E, Hiura H, Tomatsu C, Utsunomiya $\mathrm{T}$, et al. Aberrant DNA methylation of imprinted loci in sperm from oligospermic patients. Hum Mol Genet. 2007; 16(21): 25422551. 
47. Ferguson-Smith AC, Moore T, Detmar J, Lewis A, Hemberger M, Jammes H, et al. Epigenetics and imprinting of the trophoblast - a workshop report. Placenta. 2006;27(9-10):1036. Suppl A:S122-26.

48. Moore T, Haig D. Genomic imprinting in mammalian development: a parental tug-of-war. Trends Genet. 1991;7(2):45-49.

49. Kiefer JC. Epigenetics in development. Dev Dyn. 2007 Apr;236 (4): $1144-1156$

50. Horsthemke B, Ludwig M. Assisted reproduction: the epigenetic perspective. Hum Reprod Update. 2005;11(5):473-482.

51. Sferruzzi-Perri AN, Owens JA, Pringle KG, Robinson JS, Roberts CT. Maternal insulin-like growth factors-I and -II act via different pathways to promote fetal growth. Endocrinology. 2006; 147(7):3344-3355.

52. Pringle KG, Roberts CT. New light on early post-implantation pregnancy in the mouse: roles for insulin-like growth factor-II (IGF-II)? Placenta. 2007;28(4):286-297.

53. McKinnon T, Chakraborty C, Gleeson LM, Chidiac P, Lala PK. Stimulation of human extravillous trophoblast migration by IGF-II is mediated by IGF type 2 receptor involving inhibitory G protein(s) and phosphorylation of MAPK. J Clin Endocrinol Metab. 2001;86(8):3665-3374.

54. Kaufmann P, Black S, Huppertz B. Endovascular trophoblast invasion: implications for the pathogenesis of intrauterine growth retardation and preeclampsia. Biol Reprod. 2003;69(1): 1-7.
55. Solter D. Differential imprinting and expression of maternal and paternal genomes. Annu Rev Genet. 1988;22:127-46.

56. Barton SC, Surani MA, Norris ML. Role of paternal and maternal genomes in mouse development. Nature. 1984;311(5984): 374-376.

57. McGrath J, Solter D. Inability of mouse blastomere nuclei transferred to enucleated zygotes to support development in vitro. Science. 1984;226(4680):1317-9.

58. Maher ER, Afnan M, Barratt CL. Epigenetic risks related to assisted reproductive technologies: epigenetics, imprinting, ART and icebergs? Hum Reprod. 2003;18(12):2508-2511.

59. Maher ER. Imprinting and assisted reproductive technology. Hum Mol Genet. 2005;14 Spec No 1:R133-8.

Correspondencia autor: Dra. A. Cadavid Jaramillo Grupo Reproducción

Sede de Investigación Universitaria (SIU)

Universidad de Antioquia

Medellín, Colombia, Sur América, A.A. 1226

Tel: (57-4)-2196685 Fax: (57-4)-2196470

E-mail autor: cadavida@une.net.co -

reproduccion@medicina.udea.edu.co

Información artículo: Original - Infertilidad

Trabajo recibido: mayo 2008

Trabajo aceptado: julio 2008 